\title{
CIVIL LAW ASPECTS OF BANKRUPTSY OF DEBTOR'S PROPERTY
}

\author{
Irina E. Petukhova
}

Russian Presidential Academy of National Economy and Public Administration, Moscow, Russian Federation; OOO “'VIP Alliance-M’ Law Firm”, Moscow, Russian Federation

Introduction: the amount of satisfied creditors' claims in completed debtor insolvency cases raises concerns and necessitates a change in the approaches used in bankruptcy proceedings. In this connection, the author aims to study the civil law problems relating to the disposal of the debtor's property - a legal entity in bankruptcy. The research will use such general scientific methods of cognition as synthesis and analysis, as well as such specific scientific methods of cognition as systemic and formal legal ones. Results: analyzing the legal theories, law enforcement practice and the current bankruptcy legislation, the author identified the problematic issues arising from the bankruptcy of the debtor's property in bankruptcy procedures. Conclusions: adhering to the point of view that the theory of constraint of legal capacity (capability) of the debtor is fundamental in the legislative regulation of bankruptcy relations, the author identified the problematic aspects in determining the time of commencement of such constraint, the debtor's property assets to be disposed of in bankruptcy proceedings.

Key words: insolvency (bankruptcy), arbitration manager, bankruptcy of debtor's property, debtor's property, constraint of debtor's property's disposal.

Citation. Petukhova I.E. Civil Law Aspects of Bankruptsy of Debtor's Property. Legal Concept, 2019, vol. 18, no. 4, pp. 119-125. (in Russian). DOI: https://doi.org/10.15688/lc.jvolsu.2019.4.16

\section{ГРАЖДАНСКО-ПРАВОВЫЕ АСПЕКТЫ КОНКУРСНОГО РАСПОРЯЖЕНИЯ ИМУЩЕСТВОМ ДОЛЖНИКА}

\author{
Ирина Эдуардовна Петухова \\ Российская академия народного хозяйства и государственной службы при Президенте РФ, \\ г. Москва, Российская Федерация; \\ ООО «Юридическая компания “ВИП Альянс-М”», г. Москва, Российская Федерация
}

\begin{abstract}
Введение: размер удовлетворенных требований кредиторов по завершенным делам о несостоятельности должника вызывает обеспокоенность и обусловливает необходимость изменения подходов, применяемых в процедурах банкротства. В связи с этим автором поставлена цель: исследование гражданско-правовых проблем, касающихся распоряжения имуществом должника - юридического лица в банкротстве. В исследовании будут использоваться такие общенаучные методы познания, как синтез и анализ, а также частнонаучные методы - системный и формально-юридический. Результаты: анализируя правовые теории, правоприменительную практику и действующее конкурсное законодательство, автором выявлены проблемные вопросы, возникающие при конкурсном распоряжении имуществом должника в процедурах банкротства. Выводы: придерживаясь позиции о том, что теория ограничения правоспособности (дееспособности) должника является основополагающей при законодательной регламентации конкурсных правоотношений, авశ్ тор выявил проблемные аспекты при определении момента начала действия такого ограничения, состава имущества должника, подлежащего распоряжению в рамках процедур банкротства.

Ключевые слова: несостоятельность (банкротство), арбитражный управляющий, конкурсное распоряжение имуществом должника, имущество должника, ограничение распоряжения имуществом должника.
\end{abstract}


Цитирование. Петухова И. Э. Гражданско-правовые аспекты конкурсного распоряжения имуществом должника // Legal Concept = Правовая парадигма. - 2019. - T. 18, № 4. - C. 119-125. - DOI: https://doi.org/ 10.15688/lc.jvolsu.2019.4.16

\section{Введение}

Кризисные явления как в мировой, так и в российской экономике стали причиной ненадлежащего исполнения субъектами гражданского права своих обязательств. Институт банкротства (несостоятельности) в возникшей ситуации стал наиболее востребован.

По данным ЕФРСБ о сводных результатах процедур, применявшихся в деле о банкротстве за 1-й квартал 2019 г., размер удовлетворенных требований кредиторов по завершенным делам составил $3,38 \%$ от общей суммы требований, включенных в реестр требований кредиторов [9].

Размер удовлетворенных требований кредиторов по завершенным делам о несостоятельности должника вызывает обеспокоенность и обусловливает необходимость изменения подходов, применяемых в процедуpax банкротства.

При этом размер удовлетворенных заявлений о признании сделок должника недействительными по банкротным основаниям за тот же период составил $39 \%$ от общего количества принятых заявлений о признании сделок должника недействительными по данным ЕФРСБ [9].

Вышеизложенное свидетельствует о том, что распоряжение имуществом должника, осуществляемое до и после возбуждения производства по делу о банкротстве должника, обусловливает актуальность исследования правовых проблем эффективного использования и распоряжения имуществом должника. Их разрешение позволит достичь базовых целей банкротства - восстановления платежеспособности должника и наиболее полного удовлетворения требований кредиторов. В этой связи тема исследования особенно актуальна.

\section{Гражданско-правовые аспекты конкурсного распоряжения имуществом должника}

В зависимости от системы построения конкурсного законодательства распоряжение имуществом должника осуществляется следующим образом:

1. Продолжниковой системе (радикальной или умеренной) соответствует модель сохранения за должником права распоряжения имуществом в процедурах банкротства.

2. Прокредиторской системе (радикальной или умеренной) соответствует модель отстранения должника от права распоряжения имуществом и осуществления данных полномочий собранием (комитетом) кредиторов или специальным субъектом (арбитражным управляющим) в процедурах банкротства.

3. Нейтральной системе соответствует модель сохранения за должником права распоряжения имуществом при условии контролирования такого распоряжения собранием (комитетом) кредиторов или специальным субъектом (арбитражным управляющим) в процедурах банкротства.

Действующее российское конкурсное законодательство стремится обеспечить баланс интересов конкурсных отношений, в связи с чем можно с определенной степенью уверенности отнести ее к нейтральной.

В основе действующего конкурсного законодательства, регламентирующего вопросы конкурсного распоряжения имуществом, на наш взгляд, лежит теория ограничения (прекращения) правоспособности (дееспособности) должника.

Последователи теории полагают, что правоспособность (дееспособность) несостоятельного должника ограничивается (прекращается) с момента возбуждения производства по делу о несостоятельности, а восполняется арбитражным управляющим или (и) собранием (комитетом) кредиторов [4]. Данная концепция находит отражение и в судебной практике [7].

При этом полагаем необходимым отметить, что отстранение должника от распоряжения своим имуществом в силу факта признания его несостоятельным (банкротом) однозначно не свидетельствует о том, что должник одномоментно лишается правоспособности/дееспособности, а лишь указывает, что 
И.Э. Петухова. Гражданско-правовые аспекты конкурсного распоряжения имуществом должника

должник в силу такого юридического факта ограничивается в реализации своих субъективных гражданских прав, в частности права распоряжения имуществом.

В контексте ограничений осуществления должником своих субъективных прав и лишения должника права распоряжения имуществом важным представляется определение момента начала действия такого ограничения. Рассмотрим несколько вариантов.

Во-первых, ограничение и лишение должника права распоряжения может наступить с момента фактического неисполнения должником принятых обязательств [13, с. 303] (с начала течения просрочки исполнения обязательства). Такая позиция подлежит критике, поскольку просрочка исполнения обязательства может быть незначительна, само обязательство может быть дефектным и пр., соответственно, лишение и ограничение должника права распоряжения имуществом в таком случае искоренит предпринимательскую деятельность, которая сопряжена с риском.

Во-вторых, ограничение и лишение права распоряжения может наступить с момента вынесения судом определения о принятии заявления о признании должника банкротом и его опубликования. Ограничение и лишение должника права распоряжения имуществом с момента вынесения судом такого определения представляется необоснованным, поскольку введение реабилитационных и ликвидационных процедур банкротства, за исключением мирового соглашения, происходит после признания судом обоснованным заявления о признании должника банкротом, а не с момента принятия такого заявления.

В-третьих, ограничение и лишение права распоряжения имуществом может наступить с момента вынесения судом определения о признании требований заявителя обоснованным и введении наблюдения. Ограничение и лишение права распоряжения имуществом должника с момента вынесения судом такого определения возможно лишь в части установленных законом в процедуре наблюдения ограничений и запретов на распоряжение имуществом должника. Вышеуказанное свидетельствует о том, что данный вариант ограничен одной процедурой банкротства и не применим в качестве общего подхода, применимого ко всем процедурам банкротства в целом.

В-четвертых, ограничение и лишение права распоряжения имуществом может наступить с момента вынесения судебного акта о введении процедуры банкротства (определение суда о введении процедуры наблюдения, финансового оздоровления, внешнего управления, решения об открытии конкурсного производства и пр.). Судебные акты о введении процедур банкротства подлежат немедленному исполнению [11]. Лишение и ограничение права распоряжения имуществом должника является последствием введения той или иной процедуры банкротства, которые рассматриваются в настоящем исследовании через систему конкурсных запретов и ограничений распоряжения имуществом должника. Такой подход является универсальным. Вместе с тем невозможно не отметить следующую правовую ситуацию: опубликование судебных актов в сети Интернет (как резолютивной части, так и судебного акта в полном объеме) может произойти значительно позже, чем фактическая дата вынесения судебного акта, или вовсе в сети Интернет может отсутствовать судебный акт о введении процедуры, например, по техническим причинам. При опубликовании судебного акта о введении процедуры банкротства с нарушением сроков опубликования судебных актов в сети Интернет или неопубликования судебного акта третьи лица не смогут точно определить дату введения соответствующей процедуры и, следовательно, дату введения ограничений и запретов на распоряжение имуществом должника. При рассмотрении обособленных споров, связанных с оспариванием сделок должника, момент опубликования судебного акта о введении соответствующей процедуры в сети Интернет имеет юридическое значение в целях определения добросовестности контрагента должника при совершении сделки [5].

При этом стоит отметить, исходя из ст. 28 Федерального закона от 26 октября 2002 г. № 127-Ф3 «О несостоятельности (банкротстве)» и принятых во исполнение этого закона подзаконных актов, сведения о банкротстве включаются в ЕФРСБ о банкротстве и опубликовываются в газете «Коммерсантъ» $[11]$. 
Пленум ВАС РФ в пункте 7 Постановления от 23 декабря 2010 г. № 63 подчеркивает, что при рассмотрении дел, связанных с оспариванием сделок должника, существует презумпция осведомленности любого лица о наличии признаков неплатежеспособности должника при наличии публикации о введении соответствующих процедур в отношении должника [8].

В данной ситуации при оспаривании сделок должника по распоряжению имуществом, совершенных после фактической даты вынесения судебного акта о введении соответствующей процедуры банкротства, стандарты доказывания осмотрительности и добросовестности контрагента должника должны быть снижены, если установлен факт отсутствия публикации судебного акта о введении процедуры банкротства в отношении должника на дату совершения оспариваемой сделки.

В-пятых, ограничение и лишение права распоряжения имуществом должника может наступить с момента вынесения судом решения о признании должника банкротом и об открытии конкурсного производства. Ограничение и лишение права распоряжения имуществом должника с момента вынесения судом такого решения возможно, лишь исходя из установленных законом ограничений и запретов на распоряжение имуществом в процедуре конкурсного производства. Данный вариант ограничен одной процедурой банкротства и не применим в качестве общего подхода, применимого ко всем процедурам банкротства в целом.

При рассмотрении данной проблематики следует определить имущество, в отношении которого устанавливаются ограничения. Исходя из законодательной регламентации состава объектов гражданских прав [2], объекты гражданского права составляют вещи, иное имущество, имущественные права; результаты работ и оказание услуг; охраняемые результаты интеллектуальной деятельности и приравненные к ним средства индивидуализации (интеллектуальная собственность); нематериальные блага.

В связи с тем что право распоряжения исходит из правовой природы вещного права, соответственно состав имущества, подлежащего распоряжению в первую очередь, состоит из вещей (rescorporalis).
Вместе с тем возникает вопрос: а возможно ли распоряжение «бестелесными вещами» (resincorporalis), то есть иным имуществом? В соответствии с позицией А.Б. Бабаева, который полагает, что распоряжение всегда связано с вещью, распоряжение правом (в контексте отдельных правомочий собственника, или право собственности в целом) связано со свойством имущественных прав по их передаче другому лицу, то есть речи о наличии у кредитора вещных прав на имущественное право не идет [1, с. 259]. В то же время в доктрине высказываются мнения относительно необходимости разработки теоретической конструкции, похожей на правомочия собственника, но применимой к бестелесным вещам [12].

Одним из актуальных вопросов является вопрос о распоряжении биткоинами, иной криптовалютой, электронными деньгами. Законодатель в ответ на изменяющуюся действительность, бурное развитие информационных технологий пытается урегулировать данное явление: законодательными органами принят проект Федерального закона «О цифровых финансовых активах» № 419059-7 [3], Федеральный закон «О внесении изменений в части первую, вторую и статью 1124 части третьей Гражданского кодекса Российской Федерации» от 18 марта 2019 г. № 34-Ф3 [10].

В соответствии с ФЗ от 18 марта 2019 г. № 34-Ф3 число объектов гражданских прав пополнилось отдельным видом имущественных прав - цифровыми правами. Распоряжение цифровым правом или ограничение распоряжения цифровым правом возможно только в информационной системе без обращения к третьему лицу [10].

В соответствии с проектом ФЗ № 419059-7 криптовалюта квалифицируется цифровым финансовым активом, что, в свою очередь, представляет имущество в электронной форме, созданное с использованием криптографических средств. Внесение цифровых записей в реестр цифровых транзакций удостоверяет право собственности на данное имущество.

Вышеизложенное свидетельствует о попытке законодателей урегулировать правоотношения, возникающие вследствие развития информационных технологий, представляющих коммерческую ценность. Для целей вы- 
И.Э. Петухова. Гражданско-правовые аспекты конкурсного распоряжения имуществом должника

явления активов должника и признания цифровых активов имуществом должника правовое закрепление цифровых прав, криптовалюты безусловно позитивно, поскольку их реализация восполнит имущественную и конкурсную массу должника и будет способствовать эффективному восстановлению платежеспособности.

Судебная практика по делам о несостоятельности предвосхитила законодательную инициативу и установила, что биткоины относятся к иному имуществу, определенному в ст. 209 ГК РФ. Особо подчеркивается, что любое имущество должника, имеющее экономическую ценность для кредиторов (включая криптовалюту), не может быть произвольно исключено из конкурсной массы без прямо предусмотренных ст. 131, 132, 213.25 Ф3 от 26 октября 2002 г. № 127-Ф3 «О несостоятельности (банкротстве)» либо иными федеральными законами оснований [6].

Вышеизложенное позволяет сформировать понятие «конкурсное распоряжение имуществом должника», под которым понимаются правомочия как самого несостоятельного должника, так и арбитражного управляющего (в процедурах внешнего управления и конкурсного производства) по осуществлению как фактических, так и юридических действий в отношении имущества несостоятельного должника после введения процедуры банкротства должника. Под имуществом в целях конкурсного распоряжения понимаются объекты гражданских прав, имеющие коммерческую экономическую ценность для кредиторов, как принадлежащие должнику на дату введения соответствующей процедуры банкротства, так и впоследствии им полученные.

\section{Выводы}

Исследование проблематики конкурсного распоряжения имуществом должника, определение границ такого распоряжения, определение имущества, подлежащего распоряжению, - все это позволило уяснить границы правомерного распоряжения имуществом должника и, следовательно, ограничить и внести ясность в критерии добросовестности поведения субъектов, осуществляющих распоря- жение имуществом должника, и стандарты их доказывания. Вышеизложенное повлияет на основания оспаривания сделок должника по распоряжению имуществом и предмет доказывания по таким сделкам, что в конечном итоге разрешит некоторые правовые проблемы в правоотношениях с несостоятельным должником и позволит сделать процедуры банкротства более прозрачными, а соответственно - повысить доверие к использованию механизмов банкротства в экономической жизни общества.

\section{СПИСОК ЛИТЕРАТУРЫ}

1. Бабаев, А. Б. Система вещных прав : монография / А. Б. Бабаев. - М. : Волтерс Клувер, 2006. - 408 с.

2. Гражданский кодекс Российской Федерации (часть первая) от 30.11.1994 № 51-Ф3 // Собрание законодательства РФ. - 05.12.1994. - № 32. Ст. 3301.

3. Законопроект «О цифровых финансовых активах» № 419059-7.-Электрон. текстовые дан. - Режим доступа: https://sozd.duma.gov.ru/bill/419059-7. Загл. с экрана.

4. Курбатов, А. Я. Ограничение правоспособности и дееспособности юридических лиц - должников в рамках дел о несостоятельности (банкротстве) / А. Я. Курбатов, Е. С. Пирогова. - Саратов : КУБиК, 2012.- 128 с.

5. Постановление Арбитражного суда Московского округа от 06.03.2019 по делу № А40-216247/ 16. - Электрон. текстовые дан. - Режим доступа: https://kad.arbitr.ru/Card/fdfd1 cdf-6e0f-4b3b-bd9df5fae01e6072. - Загл. с экрана.

6. Постановление Девятого арбитражного апелляционного суда от 15.05.2018 по делу № А 40124668/17. - Электрон. текстовые дан. - Режим доступа: http://kad.arbitr.ru/Card/3e155cd1-6bce-478abb76-1146d2e61a4a. - Загл. с экрана.

7. Постановление Десятого арбитражного апелляционного суда от 27.03.2019 по делу № A4144625/18. - Электрон. текстовые дан. - Режим доступа: https://kad.arbitr.ru/Card/9b09c896-2834-4908b1c8-de1f56606899. - Загл. с экрана.

8. Постановление Пленума ВАС РФ «О некоторых вопросах, связанных с применением главы III.1 Федерального закона “О несостоятельности (банкротстве)”» от 23.12.2010 № 63 // Вестник ВАС РФ. - 2011. - № 3 (март).

9. Результаты процедур в делах о банкротстве за 1 кв. 2019 года. - Электрон. текстовые дан. - Режим доступа: https://fedresurs.ru/news/245629a1-5e47-4a11a142-8f128ff402ed?attempt=1. - Загл. с экрана. 
10. Федеральный закон «О внесении изменений в части первую, вторую и статью 1124 части третьей Гражданского кодекса Российской Федерации» от 18.03.2019 № 34-Ф3 // Собрание законодательства РФ. - 25.03.2019. - № 12. - Ст. 1224.

11. Федеральный закон «О несостоятельности (банкротстве)» от 26.10.2002 № 127-Ф3// Сoбрание законодательства РФ. - 28.10.2002. № 43. - Ст. 4190.

12. Федотов, Д. В. К вопросу о включении бестелесного имущества в число объектов права собственности / Д. В. Федотов // Юрист. - 2013. - № 23. C. 39-42.

13. Шершеневич, Г. Ф. Курс торгового права. T. IV: Торговый процесс. Конкурсный процесс / Г. Ф. Шершеневич ; науч. ред.: В. В. Витрянский. - М. : Статут, 2003. - 550 с.

\section{REFERENCES}

1. Babaev A.B. Sistema veshchnykh prav: monografiya [Property Rights System: Monograph]. Moscow, Wolters Kluwer Publ., 2006. 408 p.

2. Grazhdanskiy kodeks Rossiyskoy Federatsii (chast pervaya) ot 30.11.1994 № 51-FZ [Civil Code of the RF (Part One) of 30.11.1994 № 51-FZ]. Sobranie zakonodatelstva RF [Collection of Legislation of the Russian Federation], 05.12.1994, no. 32, art. 3301.

3. Zakonoproekt «O tsifrovykh finansovykh aktivakh» № 419059-7 [Bill Draft “About Digital Financial Assets” № 419059-7]. URL: https:// sozd.duma.gov.ru/bill/419059-7.

4. Kurbatov A.Ya., Pirogova E.S. Ogranichenie pravosposobnosti i deesposobnosti yuridicheskikh lits - dolzhnikov $v$ ramkakh del o nesostoyatelnosti (bankrotstve) [Restricting the Legal Capacity of Legal Entities - Debtors in the Framework of Insolvency (Bankruptcy) Cases]. Saratov, KUBiK Publ., 2012. 128 p.

5. Postanovlenie Arbitrazhnogo suda Moskovskogo okruga ot 06.03.2019 po delu № A40216247/2016 [Order of the Moscow Federal District Arbitration Court of 06.03.2019 in case № A40-216247/ 2016]. URL: https://kad.arbitr.ru/Card/fdfd1cdf-6e0f4b3b-bd9d-f5fae01e6072.

6. Postanovlenie Devyatogo arbitrazhnogo apellyatsionnogo suda ot 15.05.2018 po delu № A40-
124668/2017 [Order of the Ninth Arbitration Appeal Court of 15.05.2018 in Case № A40-124668/2017]. URL: http://kad.arbitr.ru/Card/3e155cd1-6bce-478a-bb761146d2e61a4a.

7. Postanovlenie Desyatogo arbitrazhnogo apellyatsionnogo suda ot 27.03.2019 po delu № A4144625/18 [Order of the Tenth Arbitration Appeal Court of 27.03.2019 in Case № A41-44625/18]. URL: https:// kad.arbitr.ru/Card/9b09c896-2834-4908-b1c8de1f56606899.

8. Postanovlenie Plenuma VAS RF «O nekotorykh voprosakh, svyazannykh s primeneniem glavy III.1 Federalnogo zakona «O nesostoyatelnosti (bankrotstve)» ot 23.12.2010 № 63 [Order of the Plenum of the SAC of the RF of 23.12.2010 № 63 "On Some Aspects of Using Chapter III.1 of the Russian Bankruptcy Act"']. Vestnik VAS RF [Bulletin of Court], 2011, no. 3 (March).

9. Rezultaty protsedur $v$ delakh o bankrotstve za 1 kv. 2019 goda [Results of Procedures in Bankruptcy Cases for the $1^{\text {st }}$ Quarter of 2019]. URL: https://fedresurs.ru/news/245629a1-5e47-4a11-a1428f128ff402ed?attempt $=1$.

10. Federalnyy zakon «O vnesenii izmeneniy v chasti pervuyu, vtoruyu i statyu 1124 chasti tretey Grazhdanskogo kodeksa Rossiyskoy Federatsii» ot 18.03.2019 № 34-FZ [Federal Law “About Modification of Parts the First, Second and Article 1124 of the Third Civil Code of the RF" of 18.03.2019 № 34-FZ]. Sobranie zakonodatelstva RF [Collection of Legislation of the Russian Federation], 25.03.2019, no. 12 , art. 1224 .

11. Federalnyy zakon $« \mathrm{O}$ nesostoyatelnosti (bankrotstve)» ot 26.10.2002 № 127-FZ [Russian Bankruptcy Act (Federal Law) of 26.10.2002 № 127FZ]. Sobranie zakonodatelstva RF [Collection of Legislation of the Russian Federation], 28.10.2002, no. 43, art. 4190.

12. Fedotov D.V. K voprosu o vklyuchenii bestelesnogo imushchestva $\mathrm{v}$ chislo obektov prava sobstvennosti [To the Question of Inclusion of Incorporeal Property in the Number of Objects of Ownership]. Urist, 2013, no. 23, pp. 39-42.

13. Shershenevich G.F. Kurs torgovogo prava. T. IV: Torgovyy protsess. Konkursnyy protsess [Commercial Law Course. Vol. IV: Trading Process. Bankruptcy Process]. Moscow, Statute Publ., 2003. 550 p. 
И.Э. Петухова. Гражданско-правовые аспекты конкурсного распоряжения имуществом должника

\section{Information about the Author}

Irina E. Petukhova, Postgraduate Student, Department of Civil Law and Procedure, Russian Presidential Academy of National Economy and Public Administration, Prosp. Vernadskogo, 82/1, 119574 Moscow, Russian Federation; Lawyer, OOO “'VIP Alliance-M’ Law Firm”, Admirala Lazareva St., 68, 117041 Moscow, Russian Federation, irinapetukhovae@gmail.ru, https://orcid.org/0000-0001-7478-9428

\section{Информация об авторе}

Ирина Эдуардовна Петухова, аспирант кафедры гражданского права и процесса, Российская академия народного хозяйства и государственной службы при Президенте РФ, просп. Вернадского, 82/1, 119571 г. Москва, Российская Федерация; юрист ООО «Юридическая компания “ВИП Альянс-М”», ул. Адмирала Лазарева, 68, 117041 г. Москва, Российская Федерация, irinapetukhovae@gmail.ru, https://orcid.org/0000-0001-7478-9428 